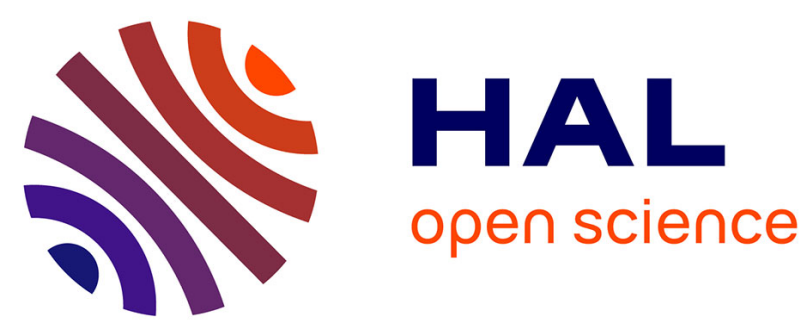

\title{
Comparison of feedback linearization and flatness control for anti-slip regulation (ASR) of an hybrid vehicle: From theory to experimental results
}

\author{
Cédric Chapuis, Eric Bideaux, Xavier Brun, Nicoleta Minoiu
}

\section{To cite this version:}

Cédric Chapuis, Eric Bideaux, Xavier Brun, Nicoleta Minoiu. Comparison of feedback linearization and flatness control for anti-slip regulation (ASR) of an hybrid vehicle: From theory to experimental results. European Control Conference (ECC), Jul 2013, Zürich, Switzerland. pp.446 - 451, 10.23919/ECC.2013.6669127 . hal-00988572

\section{HAL Id: hal-00988572 \\ https://hal.science/hal-00988572}

Submitted on 17 Apr 2019

HAL is a multi-disciplinary open access archive for the deposit and dissemination of scientific research documents, whether they are published or not. The documents may come from teaching and research institutions in France or abroad, or from public or private research centers.
L'archive ouverte pluridisciplinaire HAL, est destinée au dépôt et à la diffusion de documents scientifiques de niveau recherche, publiés ou non, émanant des établissements d'enseignement et de recherche français ou étrangers, des laboratoires publics ou privés. 


\title{
Comparison of Feedback Linearization and Flatness Control for Anti-Slip Regulation (ASR) of an Hybrid Vehicle : From Theory to Experimental Results
}

\author{
Cedric Chapuis, Eric Bideaux, Xavier Brun and Nicoleta Minoiu-Enache
}

\begin{abstract}
This paper compares 3 ASR $^{1}$ control laws, a PI controller, a linearizing feedback and a flatness based control. First, the controllers are designed based on a two state equations vehicle model. Then, the controllers are experimentally validated on an hybrid vehicle (VELROUE) with rear electric wheels and front axle $\mathrm{ICE}^{2}$ traction. Finally, the nonlinear control laws are compared to the PI controller that is classically used in the automotive industry.
\end{abstract}

\section{INTRODUCTION}

The number of hybrid and electric vehicles has increased due to technical progress in the battery field and the strengthening of ecological norms. The hybrid technology leads to the multiplication of power sources in powertrain architectures and offers new opportunities for the control of vehicles chassis dynamics. In this paper, we will consider the ASR using different control theories. A PI controller, a linearizing feedback and a flat control law are tuned on a VELROUE prototype vehicle. VELROUE is a collaborative project subsidized by FEEMA which gathers RENAULT, MICHELIN and IFP. VELROUE's demonstrator (Fig. 1) is a bi-mode powered utility vehicle with an ICE driving the front wheels and two electric motors developed by MICHELIN, clutched to both rear wheels. The developed ASR functions will be here applied to control the rear wheels slip.

VELROUE rear wheels slip is controlled by commanding the torques from the electric motors. [1] implements an ASR function using for instance a linear PID controller fed by the difference between the targeted and the measured slipping. The wheel-road contact force is computed thanks to a vehicle model similar to the model (1) used later in this paper and a

This work was supported by ANRT (CIFRE 10/169) in collaboration with RENAULT and the AMPERE LAB.

C. Chapuis is a PhD student in the Automatic Control and Mechatronic Team at Ampere Lab UMR CNRS 5005 and in the Vehicle Control Team at Renault SAS Research and Advanced Engineering Department, Renault SAS, 1 avenue du Golf, 78288 Guyancourt, France chapuis.cedric@gmail. com

Dr E. Bideaux is Professor at Ampere Lab UMR CNRS 5005 and head of Methods of System Engineering Department, 25 avenue Jean Capelle, F-69621 Villeurbanne Cedex, France eric.bideauxeinsa-lyon. fr

Dr X. Brun is Professor at Ampere Lab UMR CNRS 5005 and head of Automatic Control and Mechatronic Team, 25 avenue Jean Capelle, F-69621

Villeurbanne Cedex, France xavier.brundinsa-lyon. fr

Dr N. Minoiu-Enache is a research engineer in the Vehicle Control Team at Renault SAS Research and Advanced Engineering Department, Renault SAS, 1 avenue du Golf, 78288 Guyancourt, France nicoleta.minoiu-enachedrenault.com

${ }^{1}$ Anti-Slip Regulation

${ }^{2}$ Internal Combustion Engine

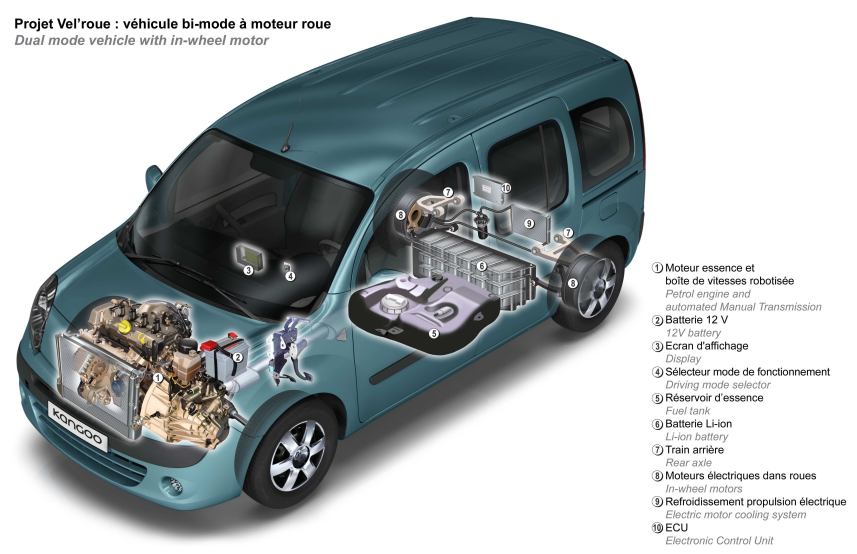

Fig. 1. VELROUE demonstrator vehicle

real time differentiation of the rotating wheel speed. Not only PID control, but also several techniques based on nonlinear control have been applied to do anti-slip regulation. A Model Following Control was used by [2] and [3]. First order sliding mode controllers were synthesized by [4], [5] and [6]. This control technique was also applied by [4] on a vehicle on rail. The sliding surface in these approaches is defined by the difference between the desired and the measured absolute slipping. This sliding mode control was applied by [5] on a vehicle with a wheel-road contact model based on the LuGre model developed in [7]. The difference with the previous papers is that the sliding surface in [6] is defined by the difference between the desired and the measured slipping ratio. For a function similar with the ASR that controls also the slip, the $\mathrm{ABS}^{3}$, a fuzzy logic control was introduced by [8] and a genetic algorithm was used to determine in real time the large number of tuning parameters required by the fuzzy logic controller. Two fuzzy controllers were also compared to a linearizing feedback control by the authors in [8]. [9] proposed the linearizing feedback control for the ASR function.

This short review of the literature shows that ASR control laws have been developed for ICE and electric vehicles. In our work the novelty consists in a comparison of a PI controller, a linearizing feedback and a flatness control, which are applied to an innovative architecture of hybrid vehicle. These controllers are developed to control the slipping of the rear wheels driven by two independent electric motors.

\footnotetext{
${ }^{3}$ AntiBlockierSystem
} 
First the vehicle model used for the synthesis of the nonlinear controllers is described in section 2. The linearizing feedback and the flat control laws are then synthesized. Experimental validation results are presented in section 3 before concluding in section IV.

\section{VEHICLE MODEL AND CONTROL LAWS SYNTHESIS}

\section{A. Vehicle Model}

The vehicle model used to synthesize the ASR controls is represented by the Bond Graph model (Fig. 3). It is based on the "bicycle" model (Fig. 2) that only considers the rotating rear wheel dynamic and the longitudinal movement.

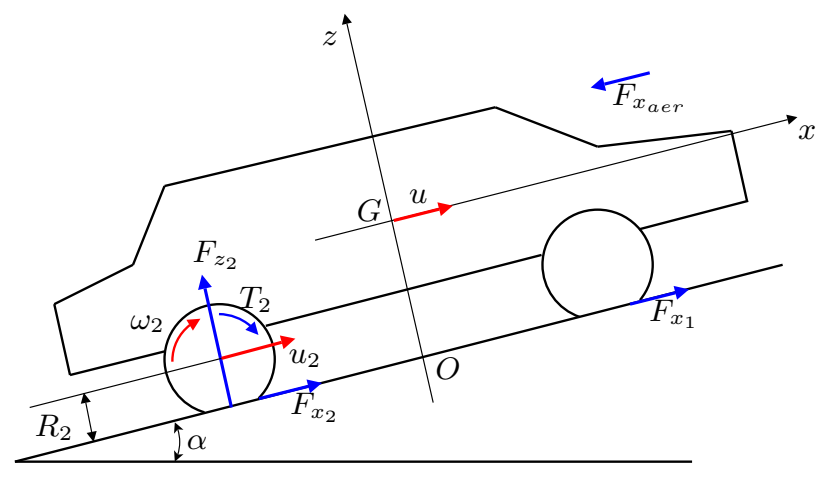

Fig. 2. Vehicle model sketch

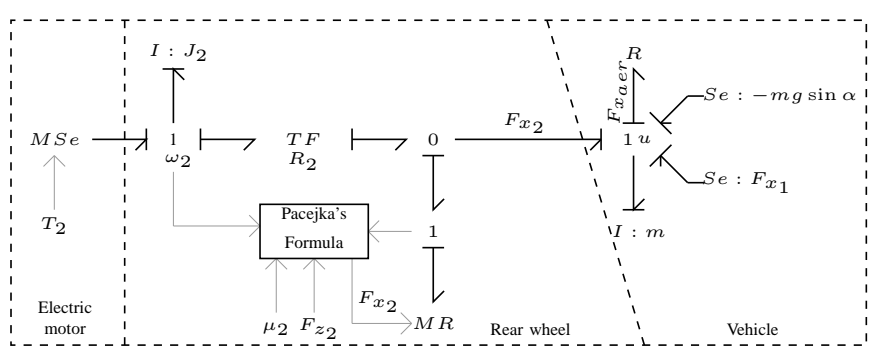

Fig. 3. Bond Graph model for control synthesis

The Bond Graph representation of the vehicle given in Fig. 3 is described by the following nonlinear two states equations model (1).

$\left\{\begin{aligned} m \dot{u} & =F_{x_{1}}+F_{x_{2}}\left(u, \omega_{2}, F_{z_{2}}, \mu_{2}\right)-F_{x_{a e r}}(u)-m g \sin \alpha \\ J_{2} \dot{\omega}_{2} & =T_{2}-R_{2} F_{x_{2}}\left(u, \omega_{2}, F_{z_{2}}, \mu_{2}\right)\end{aligned}\right.$

\section{B. Linearizing Feedback Synthesis}

During acceleration phases, the ASR function aims to maintain the rear wheels slip $\lambda_{2}$ (2) less than a constant value $\lambda_{2}^{\star}$. By differentiating (2), [9] bring up the rear wheel slipping $\lambda_{2}$ in the vehicle model (1).

$$
\begin{aligned}
& \lambda_{2}=\frac{R_{2} \omega_{2}-u}{R_{2} \omega_{2}} \\
& \dot{\lambda_{2}}=-\frac{\dot{u}}{R_{2} \omega_{2}}+\frac{u \dot{\omega}_{2}}{R_{2} \omega_{2}^{2}}
\end{aligned}
$$

$$
\left\{\begin{aligned}
m \dot{u} & =F_{x_{1}}+F_{x_{2}}\left(u, \omega_{2}, F_{z_{2}}, \mu_{2}\right)-F_{x_{a e r}}(u)-m g \sin \alpha \\
\dot{\lambda_{2}} & =\frac{u}{J_{2} R_{2} \omega_{2}^{2}} T_{2}-\frac{1}{R_{2} \omega_{2}} \dot{u}-\frac{u}{J_{2} \omega_{2}^{2}} F_{x_{2}}\left(u, \omega_{2}, F_{z_{2}}, \mu_{2}\right)
\end{aligned}\right.
$$

The front wheel-road contact force $F_{x_{1}}$ and the influence of the slope are considered as perturbations. The evolution of the slipping $\lambda_{2}$ needs to be controlled by means of rear wheel torque $T_{2}$. The system (4) has a relative degree of 1 with respect to the output $y=\lambda_{2}$. Therefore, a new control input $U$ defined by $\frac{d}{d t}\left(\lambda_{2}-\lambda_{2}^{\star}\right)=\dot{\lambda_{2}}=U$ is added to transform the vehicle model. $\lambda_{2}^{\star}$ is considered to be constant for the control law synthesis.

$$
\left\{\begin{aligned}
m \dot{u} & =F_{x_{1}}+F_{x_{2}}\left(u, \omega_{2}, F_{z_{2}}, \mu_{2}\right)-F_{x_{a e r}}(u)-m g \sin \alpha \\
\dot{\lambda_{2}} & =U
\end{aligned}\right.
$$

The driving torque $T_{2_{A S R}}$, which compensates all nonlinear terms and satisfies (5), is defined by the equation (6).

$$
T_{2_{A S R}}=\frac{J_{2} \omega_{2}}{u} \dot{u}+R_{2} F_{x_{2}}\left(u, \omega_{2}, F_{z_{2}}, \mu_{2}\right)+\frac{J_{2} R_{2} \omega_{2}^{2}}{u} U
$$

A PI-type stabilizing feedback is chosen for $U$ such that $\lambda_{2}$ converges to $\lambda_{2}^{\star}(5)$.

$$
U=-k_{p}\left(\lambda_{2}-\lambda_{2}^{\star}\right)-k_{i} \int\left(\lambda_{2}-\lambda_{2}^{\star}\right) d t
$$

An anti-windup system proposed by [10] is added to freeze the integral term when the actuator limits are reached. The linearizing feedback requires the rear wheel velocities and the longitudinal acceleration measurements in order to compute the rear wheel driving torque (6). This controller drives the rear wheels slip $\lambda_{2}$ but not the longitudinal speed of the vehicle. A partial proof of stability is presented in [11] for the residual dynamic $u$.

\section{Flat Control Synthesis}

The flat control is a linearizing control law like the other feedback presented in the previous section. In contrary to the controller developed in section II-B, the flat control is a feedforward controller which requires a flat output in order to command all system dynamics. Thus, there is no residual dynamic and the controlled system paired with a stabilizing feedback is exponentially stable outside the singularities.

In [12] a structurally flat output $y_{1}=u$ is found on the Bond Graph representation 4 of the vehicle model (1) .

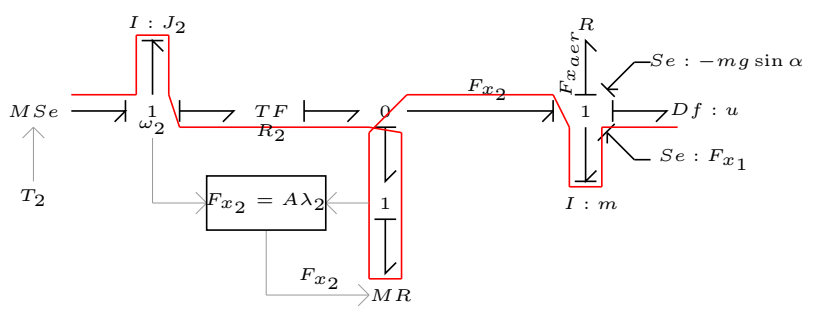

Fig. 4. Structurally flat output 
Flat control is an open loop control law. In addition, external disturbances are not predicted. Consequently, the front motor torque $T_{1}$, the drag resistance force and the influence of the road slope are neglected during the flat control design. Moreover, when the slipping is low, Pacejka's formula for the longitudinal tire force may be approximated by $F_{x_{2}}=A \lambda_{2}$ with $A$ constant (Fig. 5). The vehicle model (1) becomes hence :

$$
\left\{\begin{array}{l}
m \dot{u}=A\left(1-\frac{u}{R_{2} \omega_{2}}\right) \\
J_{2} \dot{\omega}_{2}=T_{2}-R_{2} A\left(1-\frac{u}{R_{2} \omega_{2}}\right)
\end{array}\right.
$$

To synthesize the flat control, $T_{2}$ must be expressed with respect to the flat output identified on the Bond Graph model and its derivatives. It yields to :

$$
\begin{gathered}
y_{1}=u \\
y_{2}=\dot{y}_{1}=\frac{A}{m}\left(1-\frac{u}{R_{2} \omega_{2}}\right) \\
U=y_{3}=\ddot{y}_{1}=-\frac{A}{m}\left(\frac{\dot{u} \omega_{2}-u \dot{\omega}_{2}}{R_{2} \omega_{2}^{2}}\right) \\
=-\frac{A}{m} \frac{\dot{u}}{R_{2} \omega_{2}}+\frac{A}{m} \frac{u \dot{\omega}_{2}}{R_{2} \omega_{2}^{2}} \\
T_{2}=\frac{m J_{2} y_{1} U}{A R_{2}\left(1-\frac{m}{A} y_{2}\right)^{2}}+\frac{J_{2} y_{2}}{R_{2}\left(1-\frac{m}{A} y_{2}\right)}+R_{2} m y_{2}
\end{gathered}
$$

The flat controller is not defined when $A=0$ or $A=m y_{2}$. The wheel is always supposed in contact with the road and the adherence of the road is supposed never null so, the controller is only not defined when $u=0$. When this specific case occurs, the vehicle's speed is set to a low value close to 0 .

As the flatness based controller drives the two dynamics of the system $\left(u, \omega_{2}\right)$, it can be assumed that the desired outputs are faithfully followed. In consequence, measured values can be considered equivalent to desired values in absence of perturbations. The driving torque $T_{2}$ may be expressed completely with respect to desired values denoted $y_{i}^{\star}$.

$$
T_{2}^{\star}=\frac{m J_{2} y_{1}^{\star} U^{\star}}{A^{\star} R_{2}\left(1-\frac{m}{A^{\star}} y_{2}^{\star}\right)^{2}}+\frac{J_{2} y_{2}^{\star}}{R_{2}\left(1-\frac{m}{A^{\star}} y_{2}^{\star}\right)}+R_{2} m y_{2}^{\star}
$$

The coefficient $A^{\star}$, such that $F_{x_{2}}^{\star}=A^{\star} \lambda_{2}^{\star}$, is needed to compute the torque $T_{2}$ (13) and its value is computed in real time using Pacejka's representation (Fig. 5) for a given constant adherence coefficient of the road and a vertical force to the wheel (14).

$$
A^{\star}=\frac{F_{x_{2}}^{\star}\left(\lambda_{2}^{\star}, \mu_{0}, F_{z_{0}}\right)}{\lambda_{2}^{\star}}=\frac{\phi\left(\lambda_{2}^{\star}\right) \mu_{0} F_{z_{0}}}{\lambda_{2}^{\star}}
$$

The ASR control generally tries to keep as low as possible the slip value $\lambda_{2}$. In consequence, requirements expressed

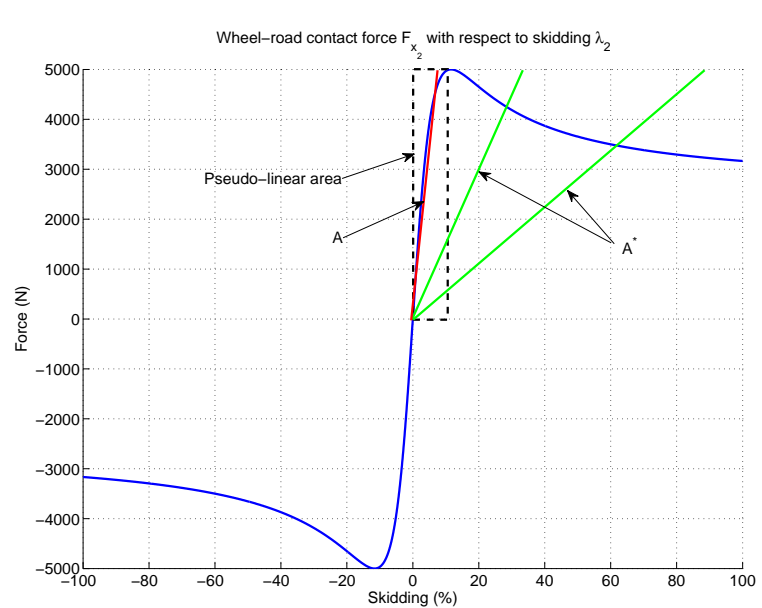

Fig. 5. Pseudo-linear area of Pacejka's representation

originally for $\lambda_{2}^{\star}$ needs to be translated, ie the trajectories of $y_{1}^{\star}$, and its derivatives $y_{2}^{\star}$ and $y_{3}^{\star}$ must be computed from $\lambda_{2}^{\star}(u)$. When the slipping is greater (less) than the desired value, the acceleration of the vehicle needs to be reduced (increased). As $y_{3}^{\star}$ is $y_{2}^{\star}$ derivative it is also $\dot{u}$ derivative. This represents the time derivative of the acceleration (jerk). Therefore, for the ASR function, $y_{3}^{\star}$ could be a function of the slipping error $e_{\lambda_{2}} \cdot y_{3}^{\star}$ is integrated to compute $y_{1}^{\star}$ and $y_{2}^{\star}$ as shown in equations (16) and (15).

$$
\begin{array}{rlrl}
y_{3}^{\star} & =K_{y_{3}} e_{\lambda_{2}} & K_{y_{3}}>0 \\
y_{2}^{\star}=\int y_{3}^{\star} d t & y_{2}^{\star}\left(t_{0}\right)=y_{2}\left(t_{0}\right) \\
y_{1}^{\star}=\int y_{2}^{\star} d t & y_{1}^{\star}\left(t_{0}\right)=y_{1}\left(t_{0}\right)
\end{array}
$$

When the open-loop control (13) is applied, the system is equivalent to a double integrator. To ensure stability, a PI error feedback defined from the slipping error $e_{\lambda_{2}}$ (19) is applied to $U^{\star}=y_{3}^{\star}$. The close loop system is exponentially stable outside the singularity $u=0$. Fig. 6 represents the final controller architecture.

$$
\begin{aligned}
T_{2} & =\frac{m J_{2} y_{1}^{\star} U}{A^{\star} R_{2}\left(1-\frac{m}{A^{\star}} y_{2}^{\star}\right)^{2}}+\frac{J_{2} y_{2}^{\star}}{R_{2}\left(1-\frac{m}{A^{\star}} y_{2}^{\star}\right)}+R_{2} m y_{2}^{\star} \\
U & =y_{3}^{\star}+K_{p} e_{\lambda_{2}}+K_{i} \int e_{\lambda_{2}} d t \\
e_{\lambda_{2}} & =\lambda_{2}^{\star}-\lambda_{2}
\end{aligned}
$$

\section{EXPERIMENTAL VALIDATION}

The vehicle has naturally four wheels however the control synthesis model considers only two. A possible approach to overcome this problem is to use 2 "bicycle" models, one for the left side of the vehicle and one for the right side. With this, each side of the vehicle has its own controller. The control laws synthesized in section II have been validated on the VELROUE prototype vehicle equipped with a MABX ${ }^{4}$.

\footnotetext{
${ }^{4}$ MicroAutoBox, dSPACE equipment
} 


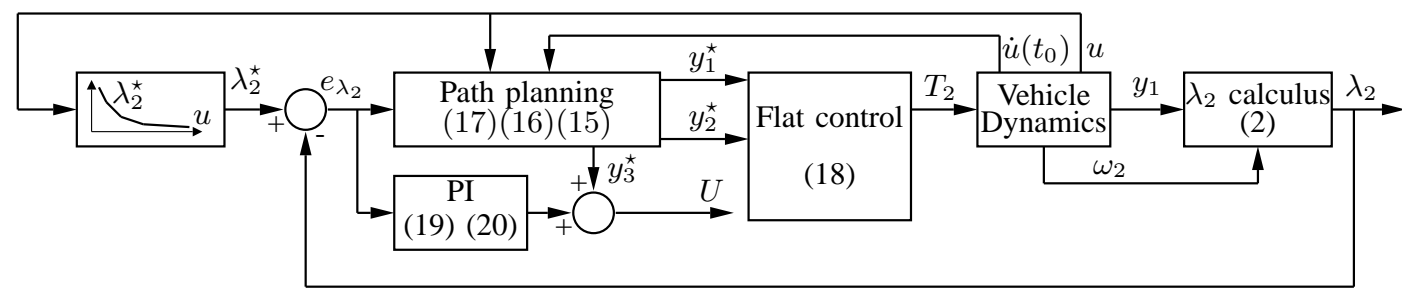

Fig. 6. Flat controller sketch

Electric motors torques, longitudinal acceleration, wheels speed and vehicle speed are measured.

In the chosen validation scenario, the vehicle is driven on a flat road with asymmetric adherence. On the left, the vehicle drives on wet tiles of constant adherence coefficient 0.2 . On the right, the coefficient varies from 0.2 to 0.7 thanks to an alternation of wet tiles and wet road. The test corresponds to an electric start up with full acceleration demand during approximatively 7 seconds followed by an acceleration release which causes an energy recovery, then an acceleration and another acceleration release. This scenario is used to study the influence of a variable and asymmetric estimation error of the adherence coefficient (the adherence coefficient is considered constant and of average value in the control law synthesis). The desired slipping $\lambda^{\star}$ varies slowly according to the vehicle's speed.

The linearizing feedback (6) and the flat controller (18) are compared to a PI controller usually used in the automotive industry. Fig. 7, 8 and 9 illustrates respectively PI controller, linearizing feedback and flat controller experimental results for the test previously described. The Fig. 7 (a), 8 (a) and 9 (a) show the left and right wheels linear velocities in continuous and dashed lines and the vehicle speed in dotted line. The slipping error Fig. (b) correspond to the difference between the measured and desired slipping. The left wheel is plotted in continuous line and the right wheel in dashed line. Fig. (c) and (d) illustrate left and right wheel torques. The motor torque asked by the driver is drawn in a continuous line while the torque computed by the ASR control law is plotted in a dashed line and the measured motor torque is in a dotted line.

At the beginning of each test when the vehicle speed is approximately zero, the rear wheels slipping error varies mainly due to noise on wheels and vehicle speeds measures. On Fig. 7 (PI controller results), when the left wheel begins to slip at 5 seconds, only the left wheel torque is quickly decreased to slow down the left wheel. The wet tiles have no gradualness so, the wheel spins quickly. The torque is then slowly increased to avoid jerks due to fast activation/deactivation of ASR. Meanwhile, the right wheel on the wet road transmits all the torque asked by the driver. Then, when the wheel is on the wet tiles, it starts to slip so, the ASR limits the right motor torque to reduce the slipping. The linearizing feedback (6) reduces correctly the rear wheels slipping error (Fig. 8). The first limitation of torque by the ASR let the wheel slip a little more than following applied torque command, for example on the
TABLE I

ASR CONTROL LAWS COMPARISON

\begin{tabular}{|c|c|c|c|}
\hline Control Law & Performance & Complexity & Tuning \\
\hline PI & - & ++ & ++ \\
Feedback Linearization & $-(+)^{5}$ & + & + \\
Flat Control & $+(++)^{5}$ & - & - \\
\hline
\end{tabular}

right wheel at 4 and 12 seconds. This extra slipping is caused by a slower response time due to $F_{x_{2}}$ estimation error rejection. The same phenomenon appears on the flat control results on Fig. 9 because of the estimation error of $A$. At 3 and $12 \mathrm{~s}$ for the left wheel and 5 and $12 \mathrm{~s}$ for the right wheel, the slipping error increases up to $80 \%$. Then, when the wheels slip again, the slipping error is limited to $20 \%$ or $40 \%$. The amplitude of torque limitation is here smaller than for the others control laws torque requests thanks to a better computing of the maximum transmissible torque. Because of higher and closer slipping error peaks, the wheels slipping control of the linearizing feedback is less effective than with the flat controller. Table I summarizes the advantages (+) and drawbacks (-) of each controller according to the performance, the complexity in terms of synthesis and implementation, and the experimental tuning difficulties.

\section{CONCLUSIONS AND FUTURE WORKS}

In this paper a linearizing feedback and a flat nonlinear control were synthesized and tested on the VELROUE prototype vehicle. These ASR functions enable the control of each rear wheel independently. Controllers presented in this paper drive properly rear wheels slipping except at the first slipping occurrence where the estimation errors needs to be rejected. The linearizing feedback is less effective than the flat controller, leading to higher and closer slipping error peaks. Future works concerning the improvement of the estimation accuracy of $F_{x_{2}}$ and $A$ will now be carried out as well as the simplification of the flat controller experimental tuning. $\mathrm{MSR}^{6}$ which is ASR counterpart for regenerative torque control will also be studied.

\section{ACKNOWLEDGMENTS}

The authors gratefully acknowledge MICHELIN and IFP, which are RENAULT partners in VELROUE project subsidized by the French Environment and Energy Management Agency.

\footnotetext{
5 If the estimation error is minimized

${ }^{6}$ Motor-Schleppmoment-Regelung
} 


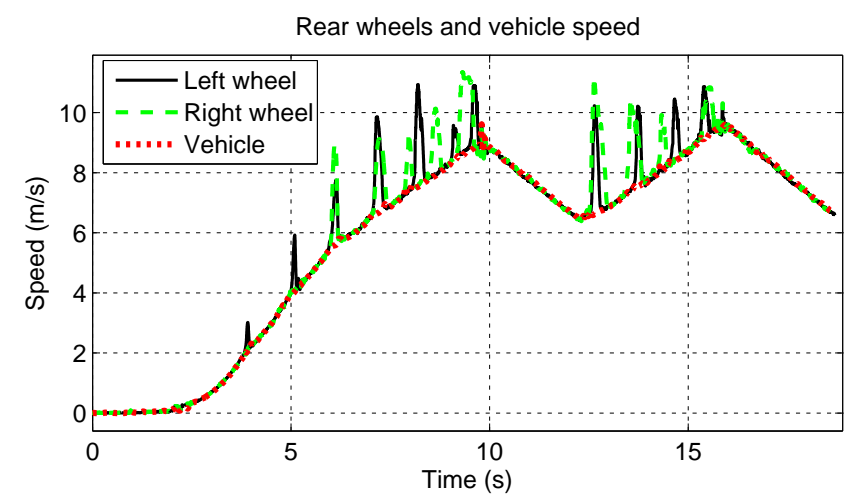

(a)

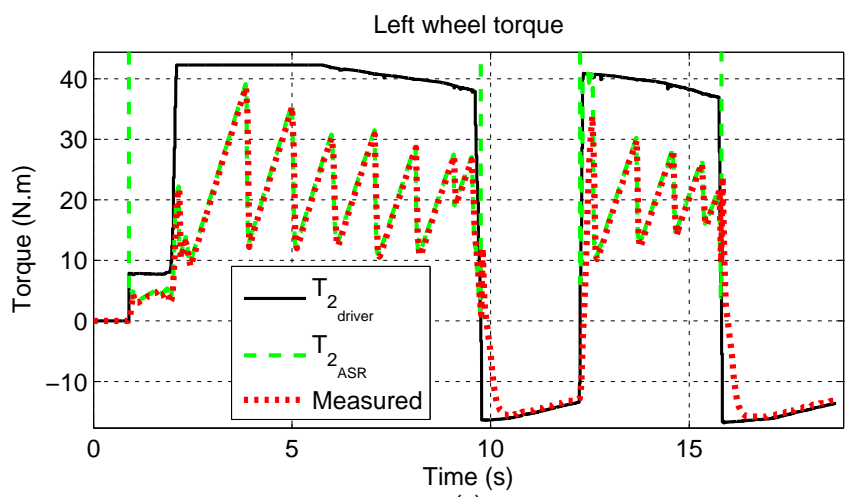

(c)

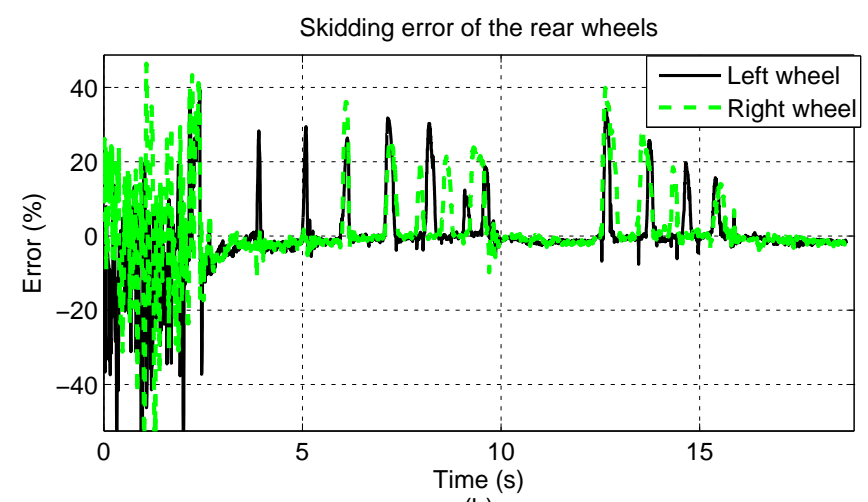

(b)

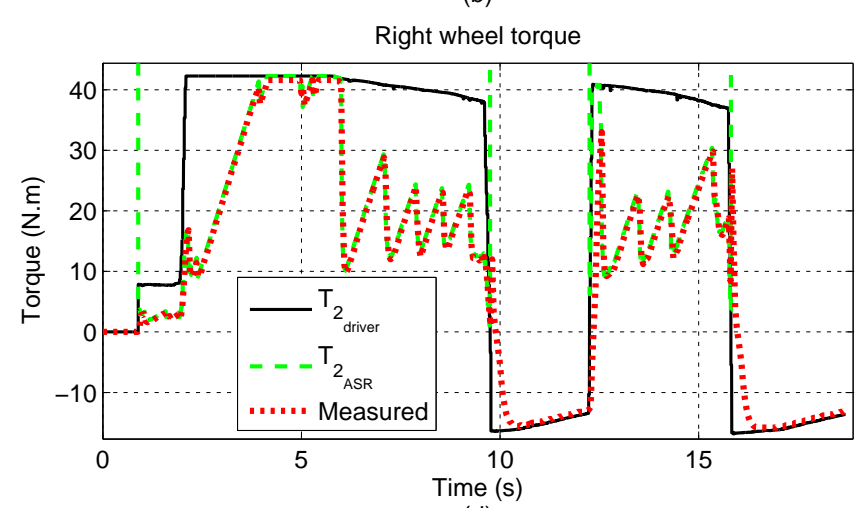

(d)

Fig. 7. PI controller experimental results
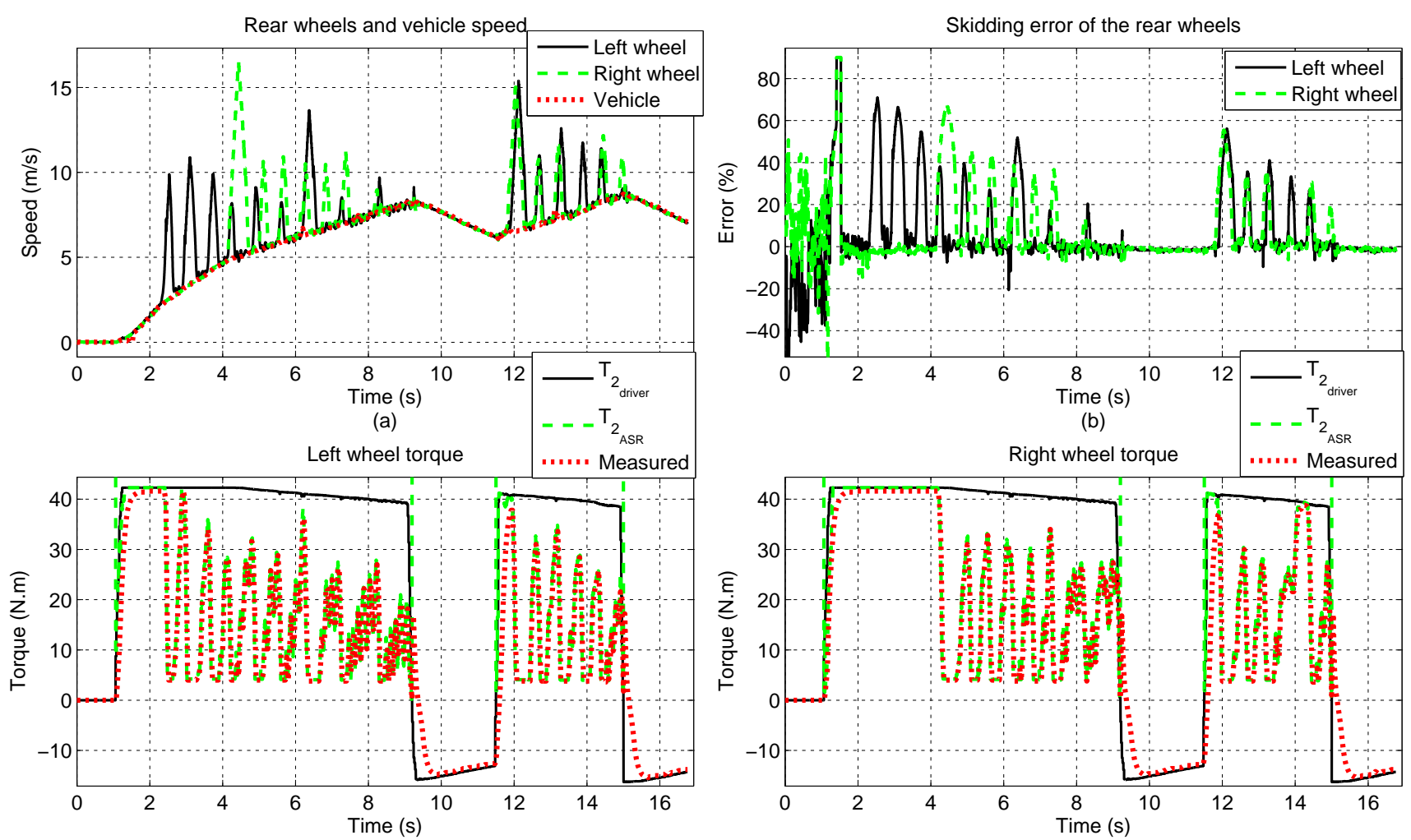

(c)

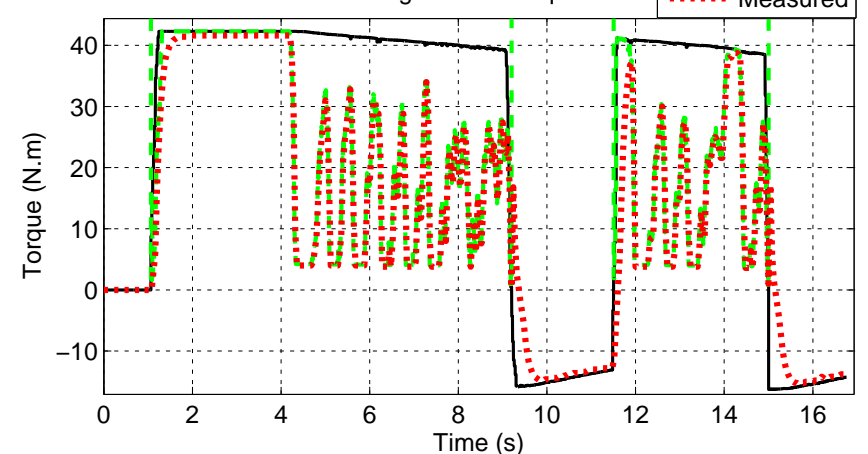

(d)

Fig. 8. Linearizing feedback experimental results 


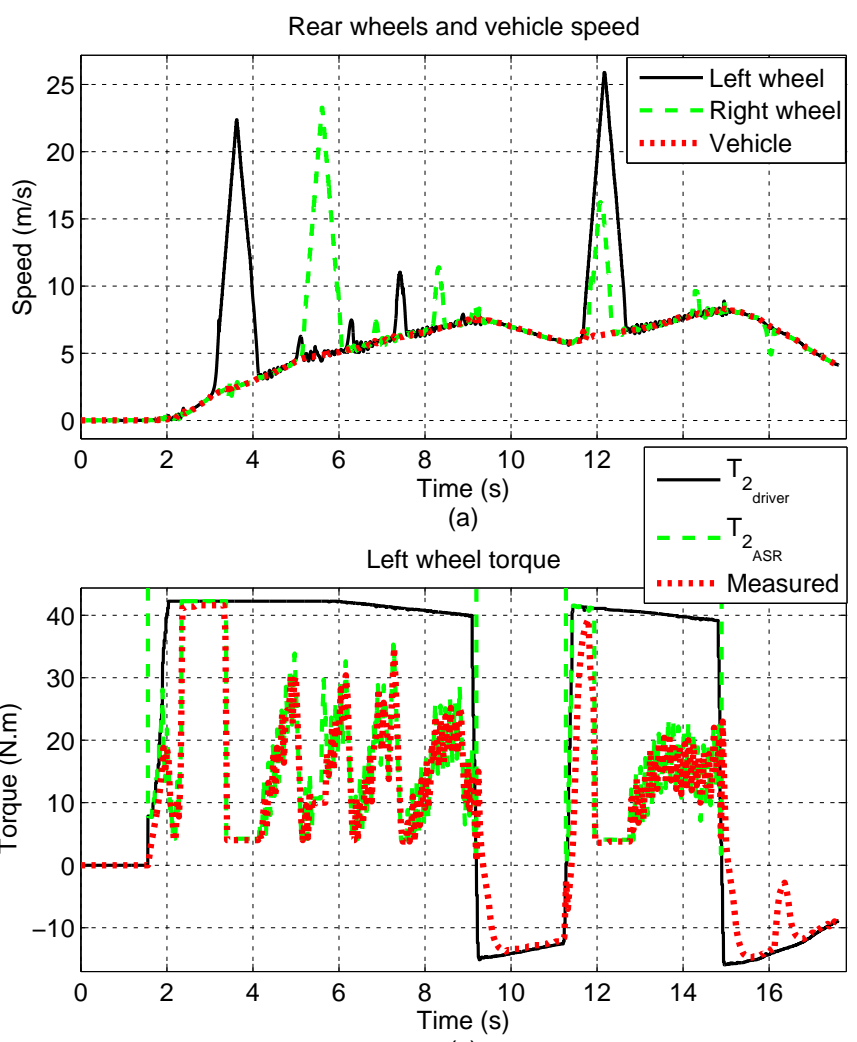

(c)

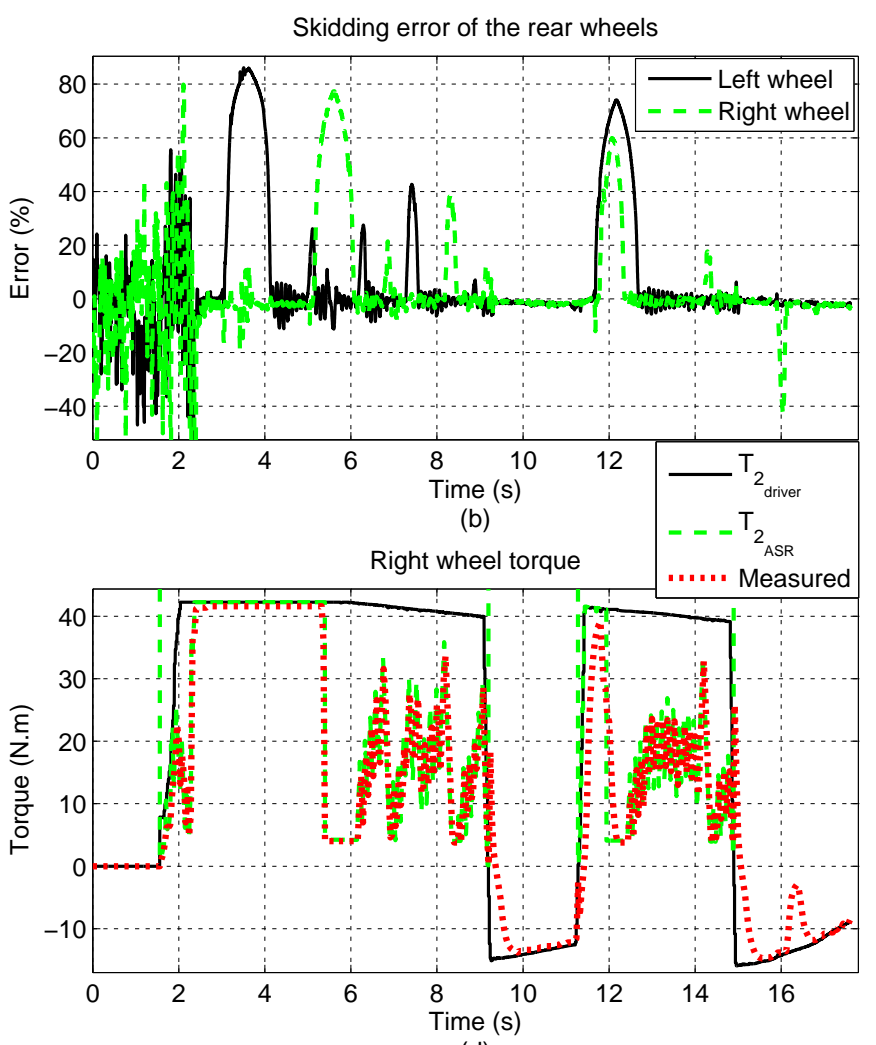

(d)

Fig. 9. Flat controller experimental results

\section{REFERENCES}

[1] J. Wang, Q. Wang, L. Jin and C. Song, Independent wheel torque control of 4WD electric vehicle for differential drive assisted steering, Mechatronics, 2011, Vol. 21, pp.63-76

[2] S. Sakai and Y. Hori, Advantage of Electric Motor for Anti Skid Control of Electric Vehicle, 2000

[3] D. Yin, S. Oh and Y. Hori, A Novel Traction Control for EV Based on Maximum Transmissible Torque Estimation, IEEE Trans. On Industrial Electronics, 2009, Vol. 56, No. 6, pp.2086-2094

[4] Z. Fan, Y. Koren and D. Wehe, A Simple Traction Control for Tracked Vehicle, Proc. of the ACC, 1995, Vol. 2, pp.1176-1177

[5] C. Canudas and P. Tsiotras, Dynamic Tire Friction Models for Vehicle Traction Control, Proc. of the IEEE CDC, 1999, Vol. 4, pp.3746-3751

[6] K. Nam and Y. Hori, Sliding mode controller design for optimal slip control of electric vehicles based on fuzzy vehicle velocity estimation logic, FISITA, 2010

[7] C. Canudas, H. Olsson, K. J. Astrm and P. Lischinsky, A new model for control of systems with friction, IEEE Trans. On Automatic Control, 1995, pp.419-425

[8] F. Chen and T. Liao, Nonlinear linearization controller and genetic algorithm-based fuzzy logic controller for ABS systems and their comparison, Int. Journal of Vehicle Design, 2000, Vol. 4, pp.334-349

[9] T. Nakakuki, T. Shen and K. Tamura, Adaptive control approach to uncertain longitudinal tire slip in traction control of vehicles, Asian Journal of Control, 2008, Vol. 10, No. 1, pp.67-73

[10] A. Visioli, Modified anti-windup scheme for PID controllers, IEE Proc. Control Theory and Applications, 2003, Vol. 150, pp.49-54

[11] C. Chapuis, N. Minoiu-Enache, X. Brun and E. Bideaux, Controle de l'anti-patinage d'un vehicule electrique par retour linearisant, CIFA, 2012

[12] C. Chapuis, X. Brun, E. Bideaux and N. Minoiu-Enache, Anti-Skid Regulation (ASR) of an Electric Vehicle Using Flatness Control, submitted to AVEC, 2012
TABLE II

LIST OF SYMBOLS

\begin{tabular}{|c|c|}
\hline$e_{\lambda_{2}}$ & rear slipping error \\
\hline$g$ & acceleration of gravity $\left(m \cdot s^{-2}\right)$ \\
\hline$m$ & mass $(k g)$ \\
\hline$u$ & component of the velocity along $x$ (m.s) \\
\hline$A$ & $\begin{array}{l}\text { approximation of Pacejka's representation } \\
\text { for low values of } \lambda_{2}(N)\end{array}$ \\
\hline$A^{\star}$ & real time approximation of Pacejka's representation $(N)$ \\
\hline$F_{x_{a e r}}$ & air resistance force $(N)$ \\
\hline$F_{x_{1}}$ & front wheel-road contact force $(N)$ \\
\hline$F_{x_{2}}$ & rear wheel-road contact force $(N)$ \\
\hline$F_{z_{2}}$ & vertical force on the rear wheel $(N)$ \\
\hline$F_{z_{0}}$ & constant vertical force used to compute $A^{\star}(N)$ \\
\hline$J_{2}$ & mass moment of inertia of the rear wheel $\left(\mathrm{kg} \cdot \mathrm{m}^{2}\right)$ \\
\hline $\bar{K}_{i}$ & stabilizing loop integral gain \\
\hline$K_{p}$ & stabilizing loop proportional gain \\
\hline$K_{y_{3}}$ & proportional gain used to plan $y_{3}$ path \\
\hline$R_{2}$ & radius of the rear wheel $(m)$ \\
\hline$T_{2}$ & rear motor torque $(\mathrm{Nm})$ \\
\hline$T_{2}{ }_{A S R}$ & rear motor torque requested by $\mathrm{ASR}(\mathrm{Nm})$ \\
\hline$T_{2}$ driver & rear motor torque requested by the driver $(\mathrm{Nm})$ \\
\hline$\alpha$ & grade angle of the road $(\mathrm{rad})$ \\
\hline$\lambda_{2}$ & slipping of the rear wheel $(\%)$ \\
\hline$\lambda_{2}^{\star}$ & desired slipping of the rear wheel $(\%)$ \\
\hline$\mu_{0}^{2}$ & constant adherence coefficient used to compute $A^{\star}$ \\
\hline$\mu_{2}$ & adherence coefficient near the rear wheel \\
\hline$\omega_{2}$ & angular velocity of the rear wheel $\left({\left.\mathrm{rad} . \mathrm{s}^{-1}\right)}^{-1}\right.$ \\
\hline$\phi(\cdot)$ & normalized Pacejka's representation \\
\hline
\end{tabular}

